\title{
Protection function of acidification pretreatment of respiratory acidosis on lung ischemia-reperfusion injury.
}

\author{
Qu Liangchao ${ }^{1}$, Jiao Yan $^{2}$, Zhan Yanping ${ }^{1}$, Jiang Zhangjie', Song Zhiping1, Zhao Weilu ${ }^{1 *}$ \\ ${ }^{1}$ Department of Anaesthesiology, The First Affiliated Hospital of Nanchang University, PR China \\ ${ }^{2}$ People's Hospital of Jiangxi, Nanchang, PR China
}

\begin{abstract}
Objective: This research was aimed to build ischemia-reperfusion model of rats in vivo, and observe the effects of different degrees of acidification pre-treatment of respiratory acidosis on lung ischemiareperfusion injury.

Methods: 50 Sprague-Dawley rats were randomly divided into five groups: the sham operation $\mathrm{S}$ group, the ischemia-reperfusion group, pretreatment $L$ group, pretreatment $M$ group and pretreatment $H$ group. Rats in all groups were killed in $2 \mathrm{~h}$ after reperfusion and ischemia. Samples of lung tissue were selected after experiments. Wet to dry weight ratio, levels of malondialdehyde, superoxide dismutase, interleukin-8 and interleukin-10 in lung tissue were detected. Pathological changes of lung tissue were observed.

Results: Compared with the sham operation group, wet to dry weight ratio, levels of malondialdehyde, superoxide dismutase, interleukin-8 and interleukin-10 in lung tissue increased obviously. Acidification pretreatment of respiratory acidosis can inhibit interleukin-8 production after ischemia-reperfusion, and lower the levels of malondialdehyde and superoxide dismutase.

Conclusion: Acidification pretreatment of respiratory acidosis can inhibit proinflammatory cytokine production after ischemia-reperfusion injury, lower inflammatory reaction level, which may protect ischemia-reperfusion injury.
\end{abstract}

Keywords: Acidification pretreatment, Respiratory acidosis, Lung ischemia-reperfusion injury.

Accepted on May 30, 2017

\section{Introduction}

Protective ventilation strategy is applied to clinics widely to improve patients' prognosis by relieving ventilator-induced lung injury. Darioli comes up with hypoventilation method that can lower death rate of patients with severe asthma obviously. After that, hypoventilation treatment can lower death rate obviously which is demonstrated by lots of basic and clinical experiments [1]. This ventilation method is called as permissive hypercapnia (PHC). This ventilation method provides the patients with hypercapnia (HC) in a certain degree to lower the death rate and lung injury. According to Protective ventilation strategy to $\mathrm{PHC}$, the proper increase of partial pressure of carbon dioxide in artery $\left(\mathrm{PaCO}_{2}\right)$ has been accepted by clinics [2]. The traditional view that its protection function has relation with lung tension which is lowered by hypoventilation. This ventilation strategy only can lower lung injury by relieving mechanical injury caused by lung traction, which has no relation with hypercapnia itself. After that, Shibata and others found that hypercapnia can lower permeability of lung capillary and injury of oxygen free radicals [3]. Laffey et al. also found that this protection appears after carbonic acid toxication, which is caused by alkaline drug and low tidal volume ventilation [4]. This suggests that acidification is the key factor of protection for lung injury of PHC. The study shows that exogenous increased carbon dioxide $\left(\mathrm{CO}_{2}\right)$ can promote $\mathrm{PaCO}_{2}$, which is regarded as therapeutic $\mathrm{HC}$ [5]. Comparing with exogenous inhalation $\mathrm{CO}_{2}$, endogenous $\mathrm{CO}_{2}$ increases by regulating respiratory frequency rate, it is also respiratory acidosis, which is more easily to be operated and controlled. This research is to study the protection function and mechanism of respiratory acidosis pretreatment of respiratory acidosis on Lung IschemiaReperfusion Injury (LIRI). Before lung ischemia-reperfusion (I/R), lung is pretreated by different degrees of respiratory acidosis through respiratory frequency rate regulation. The protection of this method is detected for lung $I / R$, which can provide simple and effective method for clinical lung $\mathrm{I} / \mathrm{R}$, and be applied to clinics conveniently.

\section{Materials and methods}

50 Sprague-Dawley (SD) male rats with weight of 250 to $300 \mathrm{~g}$ were selected. Rats were randomly divided to the five groups, each group 10 cases [6]. First, I/R group, $10 \% 5 \mathrm{ml} / \mathrm{kg}$ chloral hydrate was given intraperitoneal injection for anaesthesia. 
Trachea cannula was connected with animal respirator Remifentanil with $0.1 \mu \mathrm{g} \mathrm{kg}^{-1} \mathrm{~h}^{-1}$ rate for anesthetic maintain was pumped into vein. Cisatracurium for maintaining muscle relax was injected into vein after $40 \mathrm{~m} .0 .9 \%, 0.5 \mathrm{ml} \mathrm{h}^{-1}$ sodium chloride injection was injected into vein. Rat's experimental model was built by refering to Eppinger method [7]. Chest was opened at fifth intercostal space of left prothorax. Hilum of left lung was dissociated. $50 \mu$ hepkgarin was diluted to $500 \mathrm{U}$. Then it was injected into caudal vein (Figure 1). Hilum of left lung was closed by using noninvasive micro vascular clip in $10 \mathrm{~m}$ at the end of lung fullness. It was loosened after $45 \mathrm{~m}$ and given reperfusion for $180 \mathrm{~m}$. Second, left hilum of left lung in the sham operation group was associated after opening chest, no given other managements. Third, after association of hilum of left lung in pretreatment group, respiratory parameters were regulated. Partial pressure of carbon dioxide in end expiratory gas $\left(\mathrm{PETCO}_{2}\right)$ reached to $\mathrm{PETCO}_{2}$ in pretreatment $\mathrm{L}$ group, 56-65 $\mathrm{mm} \mathrm{Hg}$ in pretreatment group $\mathrm{M}$ group and $66-75 \mathrm{~mm} \mathrm{Hg}$ in pretreatment group $\mathrm{H}$ group for $5 \mathrm{~m}$. Then it was disposed as $\mathrm{I} / \mathrm{R}$ group. After sample selection and experiments, $2 \mathrm{ml}$ blood sample was extracted by using $5 \mathrm{ml}$. Tissue of left lung were taken off after opening chest cavity. $10 \mathrm{ml}$ Normal Saline (NS) were injected into left lung bronchus for three to four times of washing.

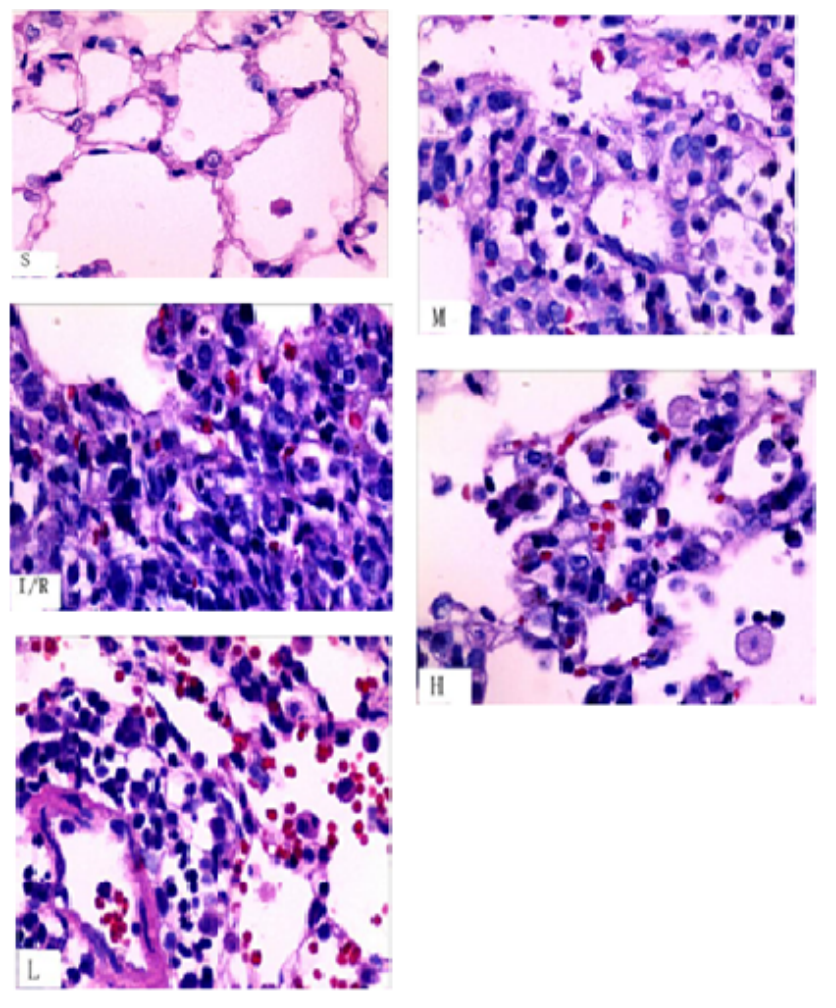

Figure 1. Histology of lung tissues in rats.

The pressure was not over $15 \mathrm{Hm}_{2} \mathrm{O}$. Injection volume was not over $3 \mathrm{ml}$ every time. Perfusate was recycled into centrifugal tube. The level of Total Protein (TP) was extracted from Broncho Alveolar Lavage Fluid (BALF). Blood sample should be placed under normal temperature. Then it was given solidification and centrifugation with $3500 \mathrm{r} / \mathrm{m}$. Liquid supernatant was collected. Then it was placed into lowtemperature refrigerator of $-80^{\circ} \mathrm{C}$ for conservation (interleukin-8 and interleukin-10 were disposed according to enzyme-linked immunosorbent assay (ELISA) kit from Hengyuan biotechnology development limited company of Shanghai). Samples of lung tissue were selected, and divided into three parts. One was used to detect wet to dry weight ratio of lung. Another was placed into refrigerator for conservation. Malon Di Aldehyde (MDA) and Superoxide Dismutase (SOD) were detected (according to kits from Jiancheng biotechnology limited company of Nanjing). Another was soaked into $10 \%$ neutral formalin, fixed and embedded with paraffin. Pathological section was made by Haematoxylin-Eosin (HE) staining.

\section{Statistical analysis}

Statistical software SPSS 15.0 was used to do statistical analysis and application. Measuring index was represented by $\overline{\mathrm{x}} \pm \mathrm{s}$. Differences among groups adopted repetitive measurement variance. Differences among groups used oneway analysis of variance (ANOVA).

\section{Ethical statement}

Ethics committee approval was obtained from the Institutional Ethics Committee of the first affiliated hospital of Nanchang University to the commencement of the study.

\section{Results}

From pathological section with HE staining, we can see that, alveoli and interstitial tissue in S group were nearly to normal lung tissue. There were a little inflammatory cells and slight edema of interstitial tissue. Structure of $\mathrm{I} / \mathrm{R}$ tissue was not clear. Lots of inflammatory cells and erythrocyte exudated from alveolar space, mesenchyme and bronchial cavity. The edema was obvious. Septum of alveoli was damaged. L, M and $\mathrm{H}$ groups compared with $\mathrm{I} / \mathrm{R}$ group, edema of alveoli and pulmonary mesenchyme, inflammatory infiltrate relieved obviously (Table 1). Compared TP in BALF, TP value in L, M, $\mathrm{H}$ groups were lower than the $\mathrm{I} / \mathrm{R}$ group, higher than the $\mathrm{S}$ group, there were statistical differences $(\mathrm{P}<0.05)$. W/D in $\mathrm{L}$, $\mathrm{M}, \mathrm{H}$ groups were lower than the $\mathrm{I} / \mathrm{R}$ group, higher than the $\mathrm{S}$ group, there were statistical differences $(\mathrm{P}<0.05)$. Wet/Dry (W/D) value among L, M, H groups decreased gradually. The detection of MDA and SOD activity of lung homogenate, MDA in L, M, H groups were lower than $\mathrm{I} / \mathrm{R}$ group, higher than the $\mathrm{S}$ group, there were statistical differences $(\mathrm{P}<0.05)$. 
Table 1. TP, W/D, MDA, SOD, IL-8 and IL-10 changes in various groups.

\begin{tabular}{llllll}
\hline Group types & $\mathbf{S}$ & I/R & L & M & H \\
\hline TP & $0.14 \pm 0.02$ & $0.37 \pm 0.04^{*}$ & $0.28 \pm 0.03^{* \#}$ & $0.25 \pm 0.04^{*}$ & $0.23 \pm 0.02^{*}$ \\
\hline W/D & $4.45 \pm 0.23$ & $5.75 \pm 0.37^{*}$ & $5.43 \pm 0.30^{* \#}$ & $5.27 \pm 0.28^{*}$ & $5.07 \pm 0.30^{*}$ \\
\hline MDA & $0.81 \pm 0.06$ & $1.31 \pm 0.08^{*}$ & $1.08 \pm 0.09^{*}$ & $0.98 \pm 0.09^{*}$ & $0.95 \pm 0.10^{*}$ \\
\hline SOD & $19.91 \pm 1.19$ & $12.35 \pm 1.15^{*}$ & $13.72 \pm 1.01^{*}$ & $14.88 \pm 1.07^{* \#}$ & $15.13 \pm 1.03^{* \#}$ \\
\hline IL-8 & $50.63 \pm 6.91$ & $77.62 \pm 9.19^{*}$ & $70.38 \pm 7.17^{*}$ & $66.62 \pm 6.95^{* \#}$ & $63.25 \pm 6.45^{* \#}$ \\
\hline IL-10 & $44.37 \pm 3.96$ & $50.63 \pm 5.48^{*}$ & $48.50 \pm 4.75$ & $46.90 \pm 3.44$ & $46.62 \pm 3.07$ \\
\hline
\end{tabular}

Notes: Compared with $S$ group, ${ }^{*} p<0.05$, compared with I/R group, ${ }^{*} p<0.05$.

MDA value among $\mathrm{L}, \mathrm{M}$ and $\mathrm{H}$ groups decreased gradually. SOD activity were higher than the $\mathrm{I} / \mathrm{R}$ group, lower than the $\mathrm{S}$ group, there were statistical differences $(\mathrm{P}<0.05)$. SOD activity among $\mathrm{L}, \mathrm{M}, \mathrm{H}$ groups increased gradually. Interleukin-8 (IL-8) and Interleukin-10 (IL-10) in lung homogenate, IL-8 in $\mathrm{L}, \mathrm{M}, \mathrm{H}$ groups were lower than $\mathrm{I} / \mathrm{R}$ group, higher than the $\mathrm{S}$ group, there were statistical differences $(\mathrm{P}<0.05)$. IL-10 in $\mathrm{L}$, $\mathrm{M}$ and $\mathrm{H}$ groups were lower than the $\mathrm{I} / \mathrm{R}$ group, higher than the $S$ group, there were statistical differences between the $I / R$ group and $\mathrm{S}$ group only $(\mathrm{P}<0.05)$. There were no statistical differences among other groups $(\mathrm{P}>0.05)$.

\section{Discussion}

This study improves ventilation strategy to increase endogenous carbon dioxide. Then respiratory acidosis internal environment is produced to reach the aim of acidizing treatment. The muscle relaxant of this study can relieve confrontation of autonomous respiration and mechanical ventilation, lung injury caused by mechanical ventilation to the greatest extent. And this study uses analgesic to relieve stress during operation and to avoid injury and liquid factor changes caused by stress reaction, which make results more credible. However, one study shows that mechanical ventilation can cause lung injury [8]. The function of lung injury has relation with low ventilation for lowering lung tension [9]. But after study shows that this protection function disappears after carbonic acidosis caused by alkaline drug and low tidal volume ventilation. This suggests that acidification is the key factor for protecting PHC of lung injury. Proper low tidal ventilation has no obvious influence in lung mechanical ventilation injury $[10,11]$. Study in clinics also shows that, low tidal ventilation in general anaesthesia changes from 8 to $10 \mathrm{ml} / \mathrm{kg}$. There are no obvious differences caused by lung mechanical ventilation [12-13]. The results of this study show that respiratory acidosis pretreatment has protection function for LIRI. It has same effects with lung injury caused by exogenous $\mathrm{CO}_{2}$.

This study shows that W/D value, TP value, IL-8 high carbon acid pretreatment $\mathrm{A}, \mathrm{B}, \mathrm{C}$ groups are higher than the $\mathrm{S}$ group, lower than the $\mathrm{I} / \mathrm{R}$ group, there are statistical differences $(\mathrm{P}<0.05)$. Indexes in $\mathrm{A}, \mathrm{B}, \mathrm{C}$ groups decrease in order. There are statistical differences between $\mathrm{A}$ and $\mathrm{C}(\mathrm{P}<0.05)$. SOD value in carbon acid pretreatment $\mathrm{A}, \mathrm{B}, \mathrm{C}$ groups were lower than $S$ group, higher than the $I / R$ group, there are statistical differences $(\mathrm{P}<0.05)$. SOD in $\mathrm{A}, \mathrm{B}, \mathrm{C}$ groups increase in order. There are statistical differences between $\mathrm{A}$ and $\mathrm{C}(\mathrm{P}<0.05)$. The results show high carbon acid ventilation strategy can lower W/D value, TP level and IL-8, reduce permeability of lung tissue, then protect lung ischemia-reperfusion injury. The study is same with before, lung ischemia-reperfusion injury can induce lung edema, inflammation, increase W/D value, TP level and IL-8. And the degree has positive correlation with W/D and TP value [14-16]. The trend of IL-10 is similar to index above. There are statistical differences between $\mathrm{I} / \mathrm{R}$ group and $\mathrm{S}$ group $(\mathrm{P}<0.05)$. There are no statistical differences among other groups $(\mathrm{P}>0.05)$. The reason may be IL-10 is anti-inflammation factor for negative regulation of inflammation. The increase of inflammation reaction stimulates its increase. Its peak appearance is later than proinflammatory factor [17-19].

LIRI can induce lung ischemia caused by many reasons (heart arrest, cardiopulmonary bypass and lung implant). Tissue recover to blood perfusion after ischemia factors appearing. Injury of cell and tissue is not relieved, but more severe. The mechanism is not very clear until now. Nowadays, the study shows that release of inflammatory medium, outburst of oxygen radical, injury of endothelial cells have important functions in LIRI [20]. Injury of endothelial cells is LIRI characteristic lesion. The main manifestations are dilation of lung capillary, rupture of epithelial cellular wall in alveoli, which increase permeability of endothelial cells and make water and protein of vessels exudation, cause migration and aggregation of inflammatory cells. Finally pulmonary edema is induced. Respiratory acidosis pretreatment for LIRI, the results of pathological section shows that, the structure of $I / R$ tissue is not clear. Lots of inflammation cells exudated from alveolar cavity, mesenchyma and bronchial cavity. The edema is obvious. Septum of alveoli is damaged. Pretreatment L, M, H groups compared with I/R group, edema of alveoli, mesenchyma and inflammatory infiltration relieve obviously.

\section{Conclusion}

In summary, our findings point to an important role for protection of acidification pretreatment of respiratory acidosis on lung ischemia-reperfusion injury. These results may open new therapeutic strategy for the management of lung $\mathrm{I} / \mathrm{R}$. 


\section{References}

1. Bigatello L M, Pesenti A. Ventilator-induced lung injury: less ventilation, less injury. Anesthesiol 2009; 111: 699-700.

2. Julie R, Gabriel H, Waldemar CA. Clinical effectiveness and safety of permissive hypercapnia. Clin Perinatol 2012; 39: 603-613.

3. Shibata K, Cregg N, Engelberts D, Takeuchi A, Fedorko L, Kavanagh BP. Hypercapnic acidosis may attenuate acute lung injury by inhibition of endogenous xanthine oxidase. Am J Respir Crit Care Med 1998; 158: 1578-1584.

4. Laffey JG, Engelberts D, Kavanagh BP. Buffering hypercapnic acidosis worsens acute lung injury. Am J Resp Crit Care Med 2000; 161: e141.

5. Marloes M, Leo M, Johannes G. Bench-to-bedside review: hypercapnic acidosis in lung injury-from 'permissive' to 'therapeutic'. Crit Care 2010; 14: e237.

6. Gilman AP, Villeneuve DC, Secours VE. Uranyl nitrate: 28-day and 91-day toxicity studies in the Sprague-Dawley rat. Toxicol Sci 1998; 41: 117-128.

7. Bellidoreyes YA, Akamatsu H, Kojima K. Cytosolic phospholipase A2 inhibition attenuates ischemiareperfusion injury in an isolated rat lung model. Transplantation 2006; 81: 1700-1707.

8. Eppinger MJ, Jones ML, Deeb GM. Pattern of injury and the role of neutrophils in reperfusion injury of rat lung. $J$ Surg Res 1995; 58: 713-718.

9. Luo Heguo, Chang Yetian, Cai Hongweil. The effect of hypercapnic acidosis pre-conditioning on rabbit myocardium. J Huazhong Univ Sci Technol Med Sci 2008; 28: 706-710.

10. Pinelopi KP, Haase VH. Molecular mechanisms of ischemic preconditioning in the kidney. Am J Physiol Renal Physiol 2015; 309: 821-834.

11. Maslov LN, Lishmanov YB, Kolar F. Hypoxic preconditioning-a phenomenon increasing the tolerance of cardiomyocytes to hypoxia/reoxygenation. Neurosci Behav Physiol 2012; 42: 380-391.
12. Wu XD, Zhang ZY, Sun S. Hypoxic pre-conditioning protects micro vascular endothelial cells against hypoxia/ reoxygenation injury by attenuating endoplasmic reticulum stress. Apoptosis 2013; 18: 85-98.

13. Brendan DH, Joseph CMC, Hassett P. Differential effects of buffered hypercapnia versus hypercapnic acidosis on shock and lung injury induced by systemic sepsis. Survey Anesthesiol 2010; 54: 216-216.

14. Maciej K, Johann P, Jerzy KW. Ischemia/reperfusion injury, its mechanisms, and prevention. J Transplantation 2013; 2012: 6130-6132.

15. Xiangqi L, Jing T, Liu D. Intratracheal administration of p38 $\alpha$ short-hairpin RNA plasmid ameliorates lung ischemia-reperfusion injury in rats. $\mathrm{J}$ Heart Lung Transplantation 2012; 31: 655-662.

16. Xiao XQ, Yong YD, Zhang SJ. Protective effects and mechanism of SP600125 on lung ischemia/reperfusion injury in rats. J Appl Physiol 2012; 28: 255-258.

17. Bing Z, Jian RY, Shi FC. The attenuation of lung ischemia reperfusion injury by oxymatrine. Cell Biochem Biophys 2014; 70: 333-336.

18. Leyla G, Murat T, Orhan Y. Taurine attenuates lung ischemia-reperfusion injury after lung transplantation in rats. J Anesth 2014; 28: 347-353.

19. Okada K, Fujita T, Minamoto K. Potentiation of endogenous fibrinolysis and rescue from lung ischemia/ reperfusion injury in interleukin (IL)-10-reconstituted IL-10 null mice. J Biol Chem 2000; 275: 21468-21476.

20. Xiao HL, Zhong HL, Hong BM. Effect of sevoflurane on tissue permeability of lung ischemia-reperfusion injury in rats. Asian Pac J Trop Med 2014; 7: 276-279.

\section{*Correspondence to}

Zhao Weilu

Department of Anaesthesiology

Hospital of Nanchang University

PR China 